\title{
Jorge Semprún y Primo Levi: escritura y memoria de los campos de concentración
}

\author{
Javier SÁNCHEZ ZAPATERO \\ Dpto. de Lengua Española (Área de Teoría de la Literatura y Literatura Comparada) \\ Universidad de Salamanca \\ zapa@usal.es
}

\begin{abstract}
RESUMEN
El artículo se ocupa de las características formales, temáticas y pragmáticas de la literatura concentracionaria, utilizando como referencia obras testimoniales de dos supervivientes de los campos nazis (Jorge Semprún y Primo Levi). Asimismo, analiza el valor memorístico y cognitivo de estos textos, nacidos con vocación de no dejar caer en el olvido los excesos cometidos en los campos ni el recuerdo de sus víctimas.
\end{abstract}

Palabras clave: literatura de campos de concentración, memoria, Primo Levi, Jorge Semprún.

\section{Jorge Semprún and Primo Levi: writing and memory about concentration camps}

\begin{abstract}
The paper studies the formal, thematic and pragmatic characteristics of concentration camp literature, using as a referente testimonial books of two survivors of the Nazi camps (Jorge Semprún and Primo Levi). Besides, it also analyzes the memorial and cognitive value of these texts, created to remember the excesses committed in the fields and the memory of its victims.
\end{abstract}

Keywords: concentration camps literature, memory, Primo Levi, Jorge Semprún.

\section{Escribir (la experiencia de) los campos de concentración}

Jorge Semprún y Primo Levi representan dos hitos fundamentales dentro de la literatura concentracionaria, y en concreto de la escrita por las víctimas del totalitarismo nazi. Su icónica condición no solo se debe a que sus obras cumplen con las principales características del corpus -singularizado, grosso modo, por su carácter universal y por acoger textos testimoniales basados en la experiencia de sus autores 
en los campos ${ }^{1}-$, sino, fundamentalmente, a la relevancia que fueron adquiriendo en el campo literario e intelectual del siglo XX y al hecho de que fueron dos de los supervivientes que más recurrentemente rememoraron a través de la escritura sus vivencias en, respectivamente, Buchemwald y Auschwitz - concretamente, en el subcampo de Monowitz-. Frente a aquellos que se limitaron a dejar testimonio por escrito de su paso por los campos de concentración en una única ocasión, intentando dar así por cerrada una etapa vital tan traumática como desgarradora-como, por ejemplo, Robert Antelme, quien después de publicar La especie humana no volvió jamás «a hablar de los campos alemanes», tal y como reconoció su por entonces esposa Margarite Duras (1999: 86)-, Semprún y Levi -al igual que otros, como Jean Améry o Imre Kertész- hicieron de sus vivencias entre alambradas tema habitual, y casi obsesivo, de su producción literaria.

El autor franco-español escribió El largo viaje (Le grand voyage, 1963), Aquel domingo (Quel beau dimanche!, 1980), La escritura o la vida (L'écriture ou la vie, 1994), Viviré con su nombre, morirá con el mío (Le mort qui'l faut, 2001) y Ejercicios de supervivencia (Exercices de survie, 2016; obra póstuma). Aunque no todas se presentan estrictamente como obras autobiográficas, es evidente que mantienen una relación de correspondencia referencial con su experiencia como preso en Buchemwald, con lo que podrían adscribirse a la categoría de «novelas del yo» con las que Manuel Alberca (2007) ha definido a los textos que transmiten vivencias personales a través de prismas de escritura ficcional. Al mismo tiempo, sus obras se imbrican de forma coherente en su trayectoria literaria, muy vinculada con su propio periplo vital, como demuestran también los casos de Adiós, luz de veranos (Adieu, vive clarté, 1998), evocación de sus años de juventud, o Autobiografía de Federico Sánchez (1977; escrita y publicada originalmente en español) y Federico Sánchez se despide de ustedes (Federico Sánchez vous salue bien, 1993), en las que se ocupa de su paso por el Partido Comunista y la actividad antifranquista clandestina. No en vano, su biógrafa Frankiska Augstein ha llegado a afirmar que «la materia de los libros de Semprún es su vida» (2010: 14). Por lo que se refiere a Levi, su estancia concentracionaria fue la base de los textos autobiográficos Si esto es un hombre (Se questo è un uomo, 1947) e Informe sobre Auschwitz (Così fu Auschwitz, 2015; obra póstuma, en la que aparece también el testimonio del superviviente Leonardo de Benedetti), de las novelas La tregua (La tregua, 1963) y Si no ahora, ¿cuándo? (Se non ora, quando?, 1982) o del ensayo Los hundidos y los salvados (I sommersi e $i$ salvati, 1986). Su ingente y variada producción confirma que, desde su liberación, consagró toda su vida a «escribir y seguir dando testimonio de su cautiverio en Auschwitz» (Muñoz Molina 2005: 9).

La recurrencia $-\mathrm{y}$ la heterogeneidad formal- con la que ambos autores abordaron su experiencia como presos puede explicarse por tres motivos, tal y como será desarrollado en las siguientes páginas: por la forma, traumática e indeleble, en la que

${ }^{1}$ Para ahondar en las características temáticas, formales y pragmáticas de la literatura concentracionaria y conocer el actual estado de la cuestión sobre su estudio, véanse los trabajos de Cohen (2006), Jurgenson (2003), Mèlich (2001), Nickel (2010), Parrau (1995) y Sánchez Zapatero (2010). 
su evolución personal fue alterada por el paso por los campos de concentración, que les llevó a rememorar una y otra vez lo vivido; por el imperativo de que dotaron a su escritura, convertida en una lucha contra el olvido a través de la que dar a conocer lo que sucedió en los campos y reivindicar la memoria de todos los que fallecieron en ellos; y por la necesidad de encontrar un modo de comunicar de forma eficaz todo lo acontecido entre alambradas, desafiando los límites de representatividad del lenguaje e intentando transmitir los inusitados niveles de violencia y horror con los que hubieron de convivir.

\section{Escribir para (sobre)vivir}

En primera instancia, los textos concentracionarios parecen surgir como reacción al deseo de los supervivientes de exonerarse interiormente dando fe de todos los tormentos pasados. Al adquirir la escritura un valor liberador, relatar lo sucedido o reflexionar sobre ello se convierte en uno de los pocos medios de que se dispone para intentar asimilar una experiencia marcada por un nivel de horror tan elevado como incomprensible, puesto que «si narrar - que es una forma, como otras muchas, de actuar-no cura el dolor, al menos lo alivia» (Caudet 2000: 25). Así lo expresó Georges Perec, para quien «hablar, escribir, son para el deportado que regresa una necesidad tan inmediata y perentoria como su necesidad de calcio, azúcar, sol, carne, sueño, silencio [... ya que] tiene que recordar y dominar ese mundo del que fue víctima» (1992: 174).

La búsqueda de un receptor atento marca todo el devenir de los supervivientes, que a medida que pasan los años siguen ansiando «un oído incansable y mortal para las voces de la muerte» (2002a: 173), como señaló Semprún en La escritura o la vida. Evidenciando el valor catártico -casi terapéutico- que en ocasiones tiene el testimonio, el autor confesó que su relato vivencial le ayudó a soportar las duras condiciones de vida de Buchemwald, como escribió en Viviré con su nombre, morirá con el mío:

Me senté al lado de aquel desconocido de mi edad. Le hablé, parecía escucharme. Le hablé de la lejana noche de la llegada a Buchenwald, la noche de nuestra llegada, juntos. Aunque su capacidad de escuchar, de prestar atención, de comprender, estaba mermada, embotada, por el abandono físico y espiritual, yo quería reavivar en él la chispa de la conciencia propia, de la memoria personal. Sólo podría interesarse de nuevo por el mundo si conseguía interesarse por sí mismo, por su propia historia. Hablé durante mucho rato, él me escuchaba [...] Yo le pagaba tabaco para que él me escuchase contarle la vida. A partir de entonces ya no hice nada más: mi vida de antes y la de Buchemwald, mezcladas, entrecruzadas. También mis sueños. Los de antes, obsesivos - «el asalto bajo el sol de los cuerpos de mujeres»- y los de Buchemwald, enfangados en la inasible y viscosa presencia de la muerte. Nadie sabrá medir objetivamente hasta qué punto esta cura fue benéfica para mí. Yo más bien tiendo a no dudarlo. (2002b: 59-61)

Análogas reflexiones efectuó Primo Levi, quien destacó el valor de estímulo de la narración autobiográfica al afirmar que «si no hubiera vivido la temporada en 
Auschwitz, es probable que nunca hubiera escrito nada» y que la necesidad de comunicar lo sucedido en el campo fue «un impulso inmediato y violento, [...] que rivalizaba con el resto de necesidades humanas más elementales» (2005: 244 y 28). La experiencia del autor italiano, que compuso Si esto es un hombre solo un par de años después del final de la guerra a pesar de no tener ni experiencia ni inquietudes literarias de ningún tipo, pone de manifiesto cómo en ocasiones el acto de escribir trasciende la mera opción personal para convertirse en una necesidad:

Tenía la impresión de que el acto de escribir equivalía para mí a tenderme en el diván de Freud. Sentía una necesidad tan imperiosa de contar, que contaba a viva voz. [...] La intención de «dejar un testimonio» surgió después, escribir como una forma de liberación fue la necesidad primera. (Camon 1996: 86-88)

\section{Escribir para (hacer) recordar}

Más allá de la liberación personal, resulta evidente que los relatos de los presos surgen con el objetivo de relatar a los demás lo ocurrido. Las vidas de los supervivientes parecen concebidas para ser contadas, tanto por su deseo de superar el pasado traumático como por la obligación que se autoimponen de informar de lo sucedido en los campos de concentración y dar voz a quienes no pudieron sobrevivir. De ahí que la memoria adquiera una doble dimensión en la literatura concentracionaria, que no solo surge del recuerdo personal, sino que además nace con la voluntad de no dejar caer en el olvido lo sucedido. Esta dualidad entre lo personal y lo colectivo ha sido explicada por Puertas Moya, para quien es necesario conjugar «la necesidad individual [...] de desahogarse y contar lo que ha vivido, con la intención [...] de que se preserve la memoria de lo sufrido» (2003: 366).

Ahora bien, la literatura concentracionaria implica también un desafío contra el desconocimiento, puesto que, como señaló Juan Gelman, «el antónimo del olvido no solo es la memoria, sino que también es la verdad» (1997). Semprún y Levi, de hecho, fueron muy conscientes de la relevancia que desde el punto de vista social y cognitivo adquiría su testimonio, gracias al que se podría conocer aquello que los responsables de los campos quisieron ocultar y que gran parte de la sociedad desconocía. El autor franco-español llegó a afirmar en El largo viaje que uno de los estímulos que más le animó a luchar por la supervivencia en el campo fue su convicción de que «era preciso contar» (2000:29) lo acontecido, mientras que en un artículo periodístico publicado coincidiendo con la conmemoración del sexagésimo aniversario de la liberación de Auschwitz reflexionó sobre los riesgos de la progresiva desaparición, por lógicas razones biológicas, de los supervivientes, y de la consiguiente ausencia de los únicos capacitados para ofrecer un relato vivencial de la experiencia concentracionaria: "Si no hay memoria de verdad, viva y verídica, ¿quién contará a las nuevas generaciones, a la de nuestros nietos, aquella historia?, ¿quién transmitirá esa memoria?» (2005: 36). Por su parte, Primo Levi insistió en Los hundidos y los salvados en la necesidad de la sociedad de «escuchar a los supervivientes, [puesto que] por encima de su experiencia individual habían sido colecti- 
vamente testigos de un acontecimiento fundamental e inesperado» (2005: 648). El autor italiano confesó que comprendió el valor pragmático y de resistencia de su escritura cuando escuchó a uno de los guardianes que le custodiaban asumir la voluntad manipuladora con la que iban a plantear el relato de lo sucedido en los campos: «De cualquier manera que termine esta guerra, la guerra contra vosotros la hemos ganado; ninguno de vosotros quedará para contarlo, pero incluso si alguno lograra escapar el mundo no le creería. [...] La historia del campo seremos nosotros quien la escriba» (2005: 457).

El valor cognitivo y memorístico de la escritura concentracionaria adquiere gran relevancia si se tiene en cuenta que los textos testimoniales de los supervivientes son -y sobre todo fueron en algún momento de la historia, fundamentalmente en los años inmediatamente posteriores al final de la Segunda Guerra Mundial- una de las pocas fuentes de información de lo que ocurrió en los campos de concentración nazis. Ideados en un estado totalitario que controlaba absolutamente todo, apenas nada se sabría de ellos si no existieran testimonios de supervivientes, pues, como ha señalado Robert Forster, la intención de los campos era dejar al mundo «sin hombre y sin habla» (1999: 242). Paradigmática de la condición de «no lugar» (Agamben 2000) de los centros concentracionarios resulta la eficacia con que se emplearon los nazis en hacer desaparecer la huellas de su política aniquiladora en los campos de exterminio, tal y como evidencian acciones como la quema o el uso con fines industriales de los cadáveres: nada quedaba de los cuerpos, nada quedaba de los hombres.

Frente a esta situación, que condenaba al anonimato y al olvido más absoluto a las víctimas, los supervivientes fueron conscientes de que sus relatos testimoniales podían ser un instrumento de resistencia a través del que difundir y dar a conocer el espacio físico y humano de los campos. Especialmente importante, en ese sentido, fue el afán de reflejar la deshumanización vivida entre alambradas, manifestado en los textos de Semprún y Levi a través de la insistencia en mostrar cómo a medida que se prolongaba el internamiento los presos iban perdiendo sus propios rasgos distintivos -el nombre, sustituido por un número; el cuerpo, convertido en un despojo de piel y huesos; el lenguaje, violentado por el desprecio con que les hablaban los guardianes a base de alaridos e insultos, e inutilizado como forma de comunicación ante el desconocimiento que en ocasiones tenían los presos del alemán, etc.-; de la frecuencia del empleo de la metáfora animalizadora para referirse lo sucedido en los campos -reflejo de que la vida en los campos no estaba regida por las leyes habituales que regulan las relaciones humanas, puesto que a los internados se les golpeaba, se les gritaba, no se les proporcionaban cubiertos para comer, no se les ofrecía intimidad... y, en general, se les trataba como si fuesen animales-; y de la constatación de que para el hombre en el campo de concentración, despojado de cualquier Rasgos Cultural, sobrevivir era único horizonte vital. Resulta sintomático comprobar cómo los dos autores se refirieron casi del mismo modo a este valor deshumanizador que convertía al hombre en un ser bestial ajeno a todo sentimiento de solidaridad y solo preocupado por satisfacer sus más primitivos instintos de supervivencia. Así, en El largo viaje Semprún aludió a cómo «en los campos de concentración, el hombre se convierte en este animal capaz de robar el pan de un compañero, de empujarle hacia la muerte» (2000: 70-71), mientras que en Si esto es un hombre 
-paradigmático título- Levi sostuvo que «es hombre quien mata, es hombre quien comete o sufre injusticias; no es hombre, quien, perdido todo recato, comparte cama con un cadáver $[\ldots \mathrm{y}]$ ha esperado que $[\ldots]$ terminase de morir para quitarle un cuarto de pan» (2005: 212).

Bajo esta función cognitiva que trata de dar a conocer el nivel de barbarie y violencia que se vivió en los campos subyace una ejemplaridad ética que dota a los relatos de los supervivientes de una dimensión pedagógica y admonitoria. De hecho, Semprún explicó en La escritura o la vida que lo esencial de la realidad concentracionaria era la «experiencia del mal»(2002a: 103-104), con lo que, teniendo en cuenta que el mal es un fenómeno intrínsecamente humano, nada aseguraba que los propios hombres volvieran a crear horrores como el representado de los campos. De forma mucho más explícita, Primo Levi advirtió de que «la historia de los campos de destrucción debería ser entendida por todos como una siniestra señal de peligro» (2005: 27) y de la necesidad de concienciar a las nuevas generaciones ante la posibilidad de que fenómenos como el nazi se repitieran: «Ha sucedido y, por consiguiente, puede volver a suceder: esto es la esencia de lo que tenemos que decir» (2005: 648).

El valor memorial que adquieren los textos también se pone de manifiesto al recordar en ellos a quienes murieron en los campos. Los supervivientes «sienten que deben contar la historia no en su nombre, sino en el de los otros», con lo que el recuerdo «se vuelve así una forma de obligación con los que se quedaron en el camino» (Escribano 2010: 339). La literatura de autores como Semprún o Levi puede interpretarse así como «una lucha contra el olvido [...], un momento ético donde los muertos cobran vida» (Cohen 2006: 17). Se escribe, por tanto, para dar voz a quien ya no la tiene ni jamás podrá tenerla, como puede observarse en un pasaje de Viviré con su nombre, morirá con el mío, en el que, tras narrar la muerte de un compañero de barracón, Semprún evoca cómo su promesa de «vivir para contar»:

No, yo no, François, yo no voy a morir. Por lo menos esta noche, te lo prometo. Voy a sobrevivir a esa noche, voy a tratar de sobrevivir a otras muchas noches para acordarme. Sin duda, y te pido perdón de antemano, a veces olvidaré. No podré siempre vivir en esta memoria mortífera. Pero volveré a este recuerdo como se vuelve a la vida [...]. Voy a tratar de sobrevivir para acordarme de ti. (2002: 226-227)

La importancia de los muertos es tal que Joan-Carles Mèlich (2001: 23) ha 1legado a denominar a los textos concentracionarios «relatos de ausencias», pues «sus protagonistas [...] no son los autores sino las víctimas que surgen en el relato, y que no han sobrevivido para poder contarlo». Este rol secundario de los supervivientes frente a los verdaderos protagonistas - quienes fallecieron en los campos- también fue expuesto por Primo Levi en Los hundidos y los salvados:

No somos nosotros, los supervivientes, los verdaderos testigos [...]. Los que hemos sobrevivido somos una minoría anómala, además de exigua: somos aquellos que sus prevaricaciones, su habilidad o suerte, no han tocado fondo. Quienes lo han hecho [...] no han vuelto para contarlo o han vuelto mudos; son ellos [...] los testigos integrales, aquellos cuya declaración habría podido tener un sentido general [...]. La 
demolición terminada, la obra cumplida, no hay nadie que la haya contado, como no hay nadie que haya vuelto para contar su muerte [...]. Nosotros hablamos por ellos como delegación. (2005: 541-542)

Quizá el pasaje del autor italiano que mejor ejemplifique la importancia de escribir para permitir dar voz a quienes no están sea la historia de Hurbinek. Incluida en La tregua, recupera del olvido la figura de un niño de tres años nacido en Auschwitz que malvivía en un barracón sin saber hablar, limitándose a emitir una serie de sonidos inconexos. Símbolo de todos los presos a los que se les negó la vida y con ello la palabra, Hurbinek representa a la víctima que habla a través de la palabra del superviviente:

\begin{abstract}
Hurbinek no era nadie, un hijo de la muerte, un hijo de Auschwitz. Parecía tener unos tres años, nadie sabía nada de él, no sabía hablar y no tenía nombre: aquel curioso nombre de Hurbinek se lo habíamos dado nosotros [...]. Estaba paralítico de medio cuerpo y tenía las piernas atrofiadas, delgadas como hilos; pero los ojos, perdidos en la cara triangular y hundida, asaeteaban atrozmente a los vivos, llenos de preguntas, de afirmaciones, del deseo de desencadenarse, de romper la tumba de su mutismo. La palabra que le faltaba y que nadie se había preocupado de enseñarle, la necesidad de la palabra, apremiaba desde su mirada con una urgencia explosiva: era una mirada salvaje y humana a la vez, una mirada madura que nos juzgaba y que ninguno de nosotros se atrevía a afrontar, de tan cargada como estaba de fuerza y dolor [...]. Hurbinek, que tenía tres años y probablemente había nacido en Auschwitz, y nunca había visto un árbol; Hurbinek, que había luchado como un hombre, hasta el último suspiro, por conquistar su entrada en el mundo de los hombres, del cual un poder bestial lo había exiliado; Hurbinek, el «sinnombre», cuyo minúsculo antebrazo había sido firmado con el tatuaje de Auschwitz; Hurbinek murió en los primeros días de marzo de 1945, libre pero no redimido. Nada queda de él: el testimonio de su experiencia son estas palabras mías. (Levi: 2005: 264)
\end{abstract}

Sin embargo, de forma paradójica, el imperativo del recuerdo y el interés por hacer presentes a las víctimas mortales de los campos provocan que el testimonio de los supervivientes nunca pueda ser completo, pues, como ha señalado Giorgio Agamben, el propio acto de «testimoniar implica la imposibilidad misma de testimoniar» (2000: 34). Del mismo modo que ninguna autobiografía puede completar el periplo vital de su autor, pues jamás podrá ocuparse de su final, los textos concentracionarios ofrecen siempre una visión parcial de lo ocurrido al no ocuparse de la muerte, elemento inherente a la realidad de los campos - tanto a la de los de exterminio como a los de internamiento, en los que las precarias condiciones y el maltrato sistemático terminaron con la vida de miles de presos-, tal y como afirmó Semprún al señalar que «en todas las matanzas de la historia hay supervivientes, [...] pero no había, jamás habría supervivientes de las cámaras de gas nazis» (2002a: 64).

\title{
4. Escribir para (intentar) comunicar
}

En consecuencia, toda literatura concentracionaria destila cierta sensación de impotencia en sus autores, incapaces tanto de transmitir con palabras una realidad 
tan inabarcable como la incardinación del mal en el mundo que suponen los campos como de convertirse en relatos globales y completos. Se pueden aportar datos y experiencias, se puede narrar con minuciosidad todo lo ocurrido, pero la capacidad testimonial no es suficiente para relatar todo el horror vivido, sobre todo cuando ni el lenguaje ni los marcos cognitivos poseen un referente a través del que comparar e interpretar lo narrado. La inefabilidad de la experiencia concentracionaria consiste en que no puede ser comprendida ni transmitida por quien la sufre, único en condiciones de comunicarla. Es el de los campos un fenómeno cuya crueldad puede ser experimentada -como ponen de manifiesto los millones de víctimas que lo sufrieron-, pero que resulta imposible de conceptuar. Así lo puso de manifiesto Semprún, quien, en palabras de su biógrafa, solo era capaz de compartir el recuerdo del campo con otros supervivientes, «con aquellos de los que sabe que conocen perfectamente de qué hablaba» (Augstein 2008: 147).

Los testimonios de los propios supervivientes ahondan en esta idea de inefabilidad y evidencian las dificultades con las que se hallaron a la hora de abordar su relato. Hasta para quien lo ha sufrido en sus propias carnes, para quien tiene recuerdos y puede hacer presente en su mente la experiencia, resulta imposible no ya expresar con palabras, sino siquiera concebir que algo tan diabólico como los campos de concentración haya existido. Primo Levi fue consciente de cómo los propios testigos eran incapaces muchas veces de creer aquello por lo que habían pasado, al señalar cómo les parecía inimaginable su propia experiencia: «Hoy, este verdadero hoy en el que estoy sentado en una mesa y escribo, yo mismo no estoy convencido de que estas cosas hayan sucedido de verdad en la realidad» (2002a: 135).

Al intentar transmitir a través de un discurso convencional lo que habían visto y sentido, los supervivientes que quisieron testimoniar tuvieron que enfrentarse a ese carácter indescriptible y, por extensión, al problema de la finitud del lenguaje. Y es que la experiencia parece reclamar un nuevo vocabulario que se ajuste al desconocido hasta entonces referente de los campos, ya que, como advirtió Primo Levi (2005: 609) «tendemos a asimilar [las experiencias narradas] a las más cercanas, como el si el hambre de Auschwitz fuese el de quien se haya saltado una comida». Utilizando uno de los iconos más representativo de los centros de exterminio nazis, Jorge Semprún (2002a: 23) demostró también cómo la concentracionaria era una realidad diferente a la convencional imposible de transmitir con el lenguaje ordinario:

Humo: todo el mundo sabe lo que es, cree saberlo. En todas las memorias de los hombres hay chimeneas que humean. Rurales ocasionalmente, domésticas: humos de dioses lares. Pero de este humo de aquí, no obstante, nada saben. Y nunca sabrán nada. [...] Nunca sabrán, no pueden imaginarlo. (2002a: 23)

La variedad formal de la obra de los dos autores estudiados en estas páginas está profundamente relacionada con estos problemas de expresión, así como con la asunción de que una realidad extraordinaria como la de los campos demandaba un nuevo modo de representación textual. En el caso de Semprún, su evocación de lo vivido en Buchemwald supuso un desarrollo inventivo y creativo, pues, al igual que otros supervivientes como Kertész, optó por estilizar su propia experiencia a la hora de 
dar cuenta de ella a través de textos como El largo viaje, La escritura o la vida o Viviré con su nombre, morirá con el mío, que en sentido estricto, y a pesar de proceder de vivencias personales, no pueden ser considerados autobiográficos:

Una duda me asalta sobre la posibilidad de contar. No porque la experiencia vivida sea indecible. Ha sido «invisible», algo del todo diferente, como se comprende sin dificultad. Algo que no atañe a la forma de relato posible, sino a su sustancia. No a su articulación, sino a su densidad. Sólo alcanzarán esa sustancia, esta densidad transparente, aquellos que sepan convertir su testimonio en un objeto artístico, en un espacio de creación. O de recreación. Únicamente el artificio de un relato dominado conseguirá transmitir parcialmente la verdad del testimonio. (2002a: 25)

Apoyada por las tesis posmodernas sobre la historiografía y la ausencia de verdades históricas únicas, esta alternativa para relatar y dar a conocer lo sucedido en los campos de concentración intenta superar los problemas de expresión derivados del unívoco carácter de la experiencia a través de la creación artística. De ahí que se considere que, de forma paradójica, el artificio pueda convertirse en mejor transmisor de lo indecible que el testimonio referencial. Frente a la verdad histórica y documental -verificable y objetiva-, la adopción de esta postura estética aboga por la verdad esencial, que no implica exactitud pero sí respeto a lo ocurrido, para conocer el pasado. De este modo, la realidad no se presenta ante el lector como una reconstrucción efectuada e impuesta por el autor, sino, más bien, como una multiplicidad que, más que aprehendida, ha ser comprendida:

Contar bien significa: de manera que se sea escuchado. No lo conseguiremos sin algo de artificio. ¡El artificio suficiente para que se vuelva arte! [...] ¿Cómo contar una historia poco creíble, cómo suscitar la imaginación de lo inimaginable si no es elaborando, trabajando un poco la realidad, poniéndola en perspectiva? ¡Pues con un poco artificio! [...] Me imagino que habrá testimonios [...] y documentos [...] y los historiadores harán obras muy eruditas. Todo se dirá, todo constará en ellas... Todo será verdad... salvo la verdad esencial, aquella que jamás ninguna reconstrucción histórica podrá alcanzar, por perfecta y omnicomprensiva que sea [...]. El otro tipo de comprensión, la verdad esencial de la experiencia, no es transmitible... O mejor dicho, sólo es transmitible mediante la escritura literaria. (Semprún 2002a: 140-141)

A pesar de que también escribió novelas a partir de su experiencia como prisionero -La tregua o Si no ahora, ¿cuándo?-, Primo Levi asumió, en términos generales, una postura diferente a la de Semprún a la hora de relatar sus vivencias en Auschwitz. Partiendo de la premisa de que los hechos han de hablar por sí mismos y de que los géneros referenciales presuponen una relación directa y transparente con la realidad que la ficción siempre altera, el autor italiano compuso textos como Si esto un hombre, paradigmático ejemplo de testimonio descriptivo, sobrio y ausente de toda retórica e inventiva, para dar cuenta de cómo se vivía en los campos y cómo se sentían los presos. Aunque la obra prescinde del orden cronológico habitual en la autobiografía y lo sustituye por una estructura temática, no hay en ella artificio ni creación alguna, pues, según las propias del propio autor, «ninguno de los datos ha sido inventado: [...] 
esto ha sucedido» (Levi 2005: 28-29). De hecho, a pesar de la ruptura de la linealidad ilativa y temporal, Si esto es un hombre impone el contrato de lectura que instauró Philippe Lejeune (1994) como fundamental para interpretar un texto como autobiográfico y, por tanto, provoca que el lector acepte tanto la identidad entre autor, lector y narrador como la veracidad de lo relatado. Además de la información del paratexto -que presenta al texto como autobiográfico, a diferencia del caso de Semprún, cuyas obras fueron incluidas en colecciones de novelas-, y de la autoridad que la condición de supervivientes da a los autores -intensificada con el paso del tiempo: quien se acerca hoy a un libro de Primo Levi lo hace en casi todos los casos conociendo su traumática vida-, algunas características de los textos orientarían ese pacto: la intención del autor de mostrarse sincero y de ceñirse a la verdad, la insistencia en utilizar verbos de percepción sensorial o relacionados con la capacidad de recordar, la referencia a otros internos o a datos históricos susceptibles de ser corroborados, etc.

A tenor de lo visto, la recurrencia con la que a lo largo de su trayectoria los dos autores abordaron el recuerdo de su paso por los campos de concentración, así como las diferentes estrategias discursivas que emplearon para relatarlo, oscilantes entre el testimonio más descarnado y la ficcionalización de la propia experiencia, no solo ha de entenderse como una manifestación de la relevancia que la memoria individual y colectiva adquiere para los supervivientes, sino también como un continuo intento de superar los desafíos que el relato de sus vivencias les imponía. De este modo se pone de manifiesto que, más allá de su carácter de fuente documental o de su condición de acto de resistencia contra una determinada visión de la historia, la literatura concentracionaria puede ser estudiada también desde una óptica formal y expresiva que analice desde prismas comparatistas la diferentes estrategias textuales a través de las que autores de un corpus universal e intercultural afrontan la representación de su experiencia en los campos. Se confirma así que, a pesar de que en textos como los de Jorge Semprún y Primo Levi el contenido parece importar más que la forma, sin la forma jamás repararíamos en el contenido.

\section{Referencias bibliográficas}

AgAmBen, Giorgio (2000): Lo que queda de Auschwitz. Valencia: Pre-textos.

AlBERCA, Manuel (2007): El pacto ambiguo: de la novela autobiográfica a la autoficción. Madrid: Biblioteca Nueva.

AugSteIn, Franziska (2010): Lealtad y traición. Jorge Semprún y su siglo. Barcelona: Tusquets.

CAmon, Ferdinando (1996): Primo Levi en diálogo con Ferdinando Camon. Salamanca: Anaya \& Mario Muchnick.

CAUDET, Francisco (2000): «Introducción biográfica y crítica», en Campo de los almendros, Max Aub, pp. 7-112. Madrid: Castalia.

COHEN, Esther (2006): Los narradores de Auschwitz. México D.F.: Fineo.

DURAS, Margarite (1999): El dolor. Barcelona: Alba.

ESCRIBANO, Asunción (2010): «La reivindicación del humanismo en la literatura europea del Holocausto», en Teoría del humanismo, Pedro Aullón de Haro (coord.), pp. 317-337. Madrid: Verbum. 
FORSTER, Robert (1999): El exilio de la palabra. En torno a lo judio. Buenos Aires: Eudeba.

Gelman, Juan (1997): «Discurso de recepción del Premio Nacional de Poesía 1994-1997». Literatura Argentina Contemporánea [en línea]. En: http://www.literatura.org/ Gelman/jgT4.html. [Consulta: 23/04/2016]

JuRGENSON, Luba (2003): L'expérience concentrationnaire est-elle indicible? París: Du Rocher.

LEJEUNE, Philippe (1994): El pacto autobiográfico y otros estudios. Madrid: Megazul Endymion.

LEVI, Primo (2005): Trilogía de Auschwitz [Si esto es un hombre, La tregua y Los hundidos y los salvados]. Barcelona: El Aleph.

MÉLICH, Joan Carles (2001): La ausencia del testimonio. Ética y pedagogía en los relatos del Holocausto. Barcelona: Anthropos.

MuÑoz MolinA, Antonio (2005: 9): «Primo Levi: el testigo sin descanso», en Trilogía de Auschwitz, Primo Levi, pp. 9-21. Barcelona: El Aleph.

NiCKEL, Claudia (2010): «Leer la literatura concentracionaria desde una perspectiva transnacional», en La littérature espagnole et les camps français d'internement (de 1939 à nos jours), Bernard Sicot (coord.), pp. 65-76. Nanterre: Université Paris Ouest Nanterre La Défense.

PARRAU, Alain (1995): Écrice le camps. París: Belin.

PEREC, Georges (1992): W o el recuerdo de la infancia. Barcelona: El Aleph.

PUERTAS MOYA, Francisco Ernesto (2003): Aproximación semiótica a los rasgos generales de la escritura autobiográfica. Logroño: Servicio de Publicaciones de la Universidad de La Rioja.

SÁNCHEZ ZAPATERO, Javier (2010): Escribir el horror. Literatura y campos de concentración. Barcelona: Montesinos.

SEMPRÚn, Jorge (2000). El largo viaje. Barcelona: Planeta Agostini.

- (2002a). La escritura o la vida. Barcelona: Tusquets.

- (2002b). Viviré con su nombre, morirá con el mío. Barcelona: Quinteto.

- (2005). «El holocausto 60 años después». El País Semanal, 23 de enero: 32-37. 